\title{
A risk-based model to assess environmental justice and coronary heart disease burden from traffic-related air pollutants
}

\author{
James P. Fabisiak ${ }^{1 *}$, Erica M. Jackson ${ }^{1}$, LuAnn L. Brink ${ }^{2}$ and Albert A. Presto ${ }^{3}$
}

\begin{abstract}
Background: Communities need to efficiently estimate the burden from specific pollutants and identify those most at risk to make timely informed policy decisions. We developed a risk-based model to estimate the burden of black carbon $(\mathrm{BC})$ and nitrogen dioxide $\left(\mathrm{NO}_{2}\right)$ on coronary heart disease (CHD) across environmental justice (EJ) and nonEJ populations in Allegheny County, PA.
\end{abstract}

Methods: Exposure estimates in census tracts were modeled via land use regression and analyzed in relation to US Census data. Tracts were ranked into quartiles of exposure (Q1-Q4). A risk-based model for estimating the CHD burden attributed to $\mathrm{BC}$ and $\mathrm{NO}_{2}$ was developed using county health statistics, census tract level exposure estimates, and quantitative effect estimates available in the literature.

Results: For both pollutants, the relative occurrence of EJ tracts ( $>20 \%$ poverty and/or $>30 \%$ non-white minority) in Q2 - Q4 compared to Q1 progressively increased and reached a maximum in Q4. EJ tracts were 4 to 25 times more likely to be in the highest quartile of exposure compared to the lowest quartile for $\mathrm{BC}$ and $\mathrm{NO}_{2}$, respectively. Pollutantspecific risk values (mean $[95 \% \mathrm{Cl})$ ) for CHD mortality were higher in EJ tracts $\left(5.49 \times 10^{-5}\left[5.05 \times 10^{-5}-5.92 \times 10^{-5}\right]\right.$; $5.72 \times 10^{-5}\left[5.44 \times 10^{-5}-6.01 \times 10^{-5}\right]$ for $\mathrm{BC}$ and $\mathrm{NO}_{2}$, respectively) compared to non-EJ tracts $\left(3.94 \times 10^{-5}\left[3.66 \times 10^{-5}\right.\right.$ $\left.-4.23 \times 10^{-5}\right] ; 3.49 \times 10^{-5}\left[3.27 \times 10^{-5}-3.70 \times 10^{-5}\right]$ for $\mathrm{BC}$ and $\mathrm{NO}_{2}$, respectively). While EJ tracts represented $28 \%$ of the county population, they accounted for about $40 \%$ of the CHD mortality attributed to each pollutant. EJ tracts are disproportionately skewed toward areas of high exposure and EJ residents bear a greater risk for air pollution-related disease compared to other county residents.

Conclusions: We have combined a risk-based model with spatially resolved long-term exposure estimates to predict CHD burden from air pollution at the census tract level. It provides quantitative estimates of effects that can be used to assess possible health disparities, track temporal changes, and inform timely local community policy decisions. Such an approach can be further expanded to include other pollutants and adverse health endpoints.

Keywords: Environmental justice, Air pollution, Nitrogen dioxide, Black carbon, Coronary heart disease, Risk assessment, Land use regression modeling

\footnotetext{
* Correspondence: fabs@pitt.edu

'Center for Healthy Environments \& Communities, Department of Environmental \& Occupational Health, University of Pittsburgh Graduate School of Public Health, PUBHL-4132, 130 DeSoto Street Pittsburgh, Pittsburgh, PA 15261, USA

Full list of author information is available at the end of the article
}

(c) The Author(s). 2020 Open Access This article is licensed under a Creative Commons Attribution 4.0 International License, which permits use, sharing, adaptation, distribution and reproduction in any medium or format, as long as you give appropriate credit to the original author(s) and the source, provide a link to the Creative Commons licence, and indicate if changes were made. The images or other third party material in this article are included in the article's Creative Commons licence, unless indicated otherwise in a credit line to the material. If material is not included in the article's Creative Commons licence and your intended use is not permitted by statutory regulation or exceeds the permitted use, you will need to obtain permission directly from the copyright holder. To view a copy of this licence, visit http://creativecommons.org/licenses/by/4.0/. The Creative Commons Public Domain Dedication waiver (http://creativecommons.org/publicdomain/zero/1.0/) applies to the data made available in this article, unless otherwise stated in a credit line to the data. 


\section{Background}

The adverse health effects from elevations in ambient air pollution are well established. Notable pollutants of concern, for which National Ambient Air Quality Standards are set by the US EPA, include ozone, sulfur dioxide, nitrogen dioxide $\left(\mathrm{NO}_{2}\right)$, lead, carbon monoxide and particulate matter (PM). Separate standards for PM exist based on its size profile; $\mathrm{PM}_{10}(<10 \mu \mathrm{m}$ mean aerodynamic diameter, MADD) and $\mathrm{PM}_{2.5}(<2.5 \mu \mathrm{m}$ MADD), with smaller particles being the primary health concern. In contrast to the other pollutants, PM is chemically and physically diverse depending in large part on its source.

The relationship between exposure to air pollution and adverse health outcomes, some severe, has been demonstrated now in multiple epidemiological and other studies. Elevations in exposure to several of the criteria air pollutants have been associated with premature overall mortality $[1,2]$, exacerbation of respiratory disease like asthma [3-5], adverse birth outcomes [6,7], increased rate of hospitalizations $[8,9]$ and death from cardiovascular disease [10-12]. Practical limitations in routinely conducting these largescale health effect studies, however, include the requirements of a large population and long study duration in order to achieve statistical power, sufficient access to patient health records over the study period, and exposure estimates are often limited by poor spatial resolution.

Pittsburgh, a major US city, sits in Allegheny County located in the southwest corner of Pennsylvania. The region has a legacy of heavy industrialization, and even today, air pollution remains problematic compared to many other areas of the US [13-15]. Like any urban center, residents are exposed to pollutants such as diesel exhaust particulates and $\mathrm{NO}_{2}$ from the high density of motor vehicles. Uniquely, Allegheny County still contains numerous highemitting industrial point sources of pollution mostly related to the coal, steel, and metals industries. In addition, long-range transport from other industrial centers in the Midwest and a propensity for meteorological thermal inversions in low-lying river valley areas trapping pollutants also add to the burden. Parts of Allegheny County remain in non-attainment for $\mathrm{PM}_{2.5}$ and, along with some surrounding counties, are in non-compliance of the $\mathrm{SO}_{2}$ standard [16]. Removal of ozone non-attainment status for Southwest PA has only recently been recommended by the PA Dept. of Environmental Protection and is pending EPA approval [17]. It is also important to consider that with limited spatial distribution of regulatory air monitors and, the fact that recent large population studies $[18,19]$ indicate health effects are appreciable at levels below ambient standards, it is likely that air pollution exposures and, hence, health burden are heterogeneously distributed across the region.

Therefore, there is continuing and increasing need for communities to be able to estimate the potential impact of air pollution on their residents. Based on the technical limitations of conducting adequate large-scale epidemiological studies described above, it is often impractical to gather empirical disease incidence data to inform decisions in a timely fashion and as they may relate to neighborhood heterogeneity. Many of the epidemiological studies performed elsewhere, however, do provide quantitative effect estimates describing the relationship between exposure level and disease incidence that can then be applied in risk-based models to estimate the disease burden associated with specific exposures.

While spatial maps of pollutants have been employed in epidemiological studies that associate incidence of disease with exposure [20, 21], few studies have linked spatial gradients of exposure at predicting or modeling disease at the community and neighborhood level using low-cost, timeefficient risk-based models. Estimations of disease burden from air pollution exist but these are frequently calculated at the global level $[22,23]$. Correlation of spatial maps of $\mathrm{NO}_{2}$ exposure with demographics have revealed disparities by race and income over the entire U.S. [24, 25], however, more granular insight and consideration of health inequities is needed for policy to advance at the community level.

We sought to develop a risk-based model that would allow us to combine existing land use regression (LUR) models describing the geographic distribution of particular pollutants within Allegheny County with high spatial resolution along with published health effect estimates [20]. From this we could estimate air pollution-dependent disease burdens at the census tract level, including those designated as environmental justice (EJ) tracts based on race and income. We selected $\mathrm{NO}_{2}$ and black carbon (BC) as two model pollutants. $\mathrm{NO}_{2}$ derives primarily from both gasoline and diesel-powered motor vehicles with smaller contributions coming from industrial sources, in particular regional coal-fired power plants [15]. BC is a component of particulate matter and serves as a surrogate for the combustionrelated $\mathrm{PM}_{2.5}$ components [26]. Primary PM sources in Allegheny County again include traffic-related particulates primarily from diesel exhaust, but also significant contributions from industrial point sources especially related to coke processing, steel manufacture, metal fabrication, as well as, residential wood burning [14]. Both pollutants are associated with adverse cardiovascular events and we chose increased mortality and hospitalization from coronary heart disease as a specific health endpoint of interest [20, 27, 28]. By coupling spatial exposure and health effect estimates with demographic US census data we calculate the hypothetical excess $\mathrm{CHD}$ burden arising from $\mathrm{NO}_{2}$ and $\mathrm{BC}$ exposure and show that EJ sensitive areas are were more numerous in areas of higher exposure and bear a disproportionate amount of risk of $\mathrm{CHD}$ from air pollution compared to non-EJ areas. 


\section{Methods}

\section{Land use regression exposure estimates}

Pollutant exposures were assigned based on land use regression (LUR) models for $\mathrm{BC}$ and $\mathrm{NO}_{2}$. LUR modeling and pollutant data collection are described by Tan et al. [29] and Li et al. [30]. Briefly, pollutant data was collected via mobile sampling to measure pollutants including $\mathrm{BC}$ (Magee Scientific AE31 Aethalometer) and $\mathrm{NO}_{2}$ (Teledyne API T200). Mobile sampling was conducted at 42 sites in Allegheny County during winter (2011-2012) and summer (2012) with each site sampled in the morning (5$11 \mathrm{AM}$ ), afternoon/evenings (11 AM - 9 PM) and overnight $(9 \mathrm{PM}-5 \mathrm{AM})$ in each season. The sites were selected using random sampling stratified by elevation (valley or upland) and traffic volume (high or low traffic). Eight sites were valley sites with low traffic, 11 sites were valley sites with high traffic, 13 sites were upland sites with low traffic, and 10 sites were upland sites with high traffic. The mobile laboratory was driven along a prescribed driving route at each site.

The time series of $\mathrm{BC}$ data includes many short-duration spikes attributable to diesel vehicles [31]. Thus, we constructed, as described by Tan et al. [29], a hybrid BC LUR that separates short-term spikes from the rest of the $\mathrm{BC}$ signal. Spikes are attributed to on-road diesel traffic, and the remaining signal is used to construct an LUR model for the background (non-traffic) BC. The final BC spatial model is the sum of the vehicle plume layer and the background LUR.

We constructed a separate LUR for $\mathrm{NO}_{2}$. The $\mathrm{NO}_{2}$ time series did not exhibit high concentration spikes, therefore we did not decompose the signal as with BC. The LUR model was fit to the mean $\mathrm{NO}_{2}$ concentration at each of the 42 sampling locations.

The background BC LUR and the $\mathrm{NO}_{2}$ LUR both follow the stepwise variable selection process used in the ESCAPE project [32]. Each land-use covariate is assigned a prior direction, either a positive or negative regression coefficient. For example, traffic emissions contribute to $\mathrm{NO}_{2}$, so all covariates related to vehicle traffic are assumed to have a positive coefficient. Land-use covariates are added to the model if they increase the model $R^{2}$ by more than 0.01 . Variables are removed if their $p$-value is greater than 0.1 or if the variance inflation factor is greater than 3 . Both $\mathrm{NO}_{2}$ and $\mathrm{BC}$ spatial models were evaluated using leave one out cross validation and by testing predictions against a hold-out dataset collected at an additional 30 sites in 2013-2014. The BC and $\mathrm{NO}_{2}$ LURs are representative of long-term (e.g., annual) average concentrations. The $\mathrm{R}^{2}$ for the $\mathrm{BC}$ model is 0.67 , and 0.76 for the $\mathrm{NO}_{2}$ model.

The LUR outputs are grid-cell averages for each cell, initially computed at $10 \mathrm{~m}$ resolution and then downaveraged. For example, each $50 \mathrm{~m} \times 50 \mathrm{~m}$ cell in the final prediction raster can be divided into a grid of 36 nodes each separated by $10 \mathrm{~m}$. We compute the circular buffers around each of those nodes to generate LUR predictions at each node, then compute the average across all nodes within each $50 \mathrm{~m} \times 50 \mathrm{~m}$ grid cell. This average is what is shown in the high-resolution black and white maps in Fig. 1. The assigning of an exposure level to a given census tract was then taken as the arithmetic mean of all the grid cells contained within the boundaries of that tract.

\section{Demographic data and EJ designation}

Identity of EJ-sensitive census tracts within Allegheny County were obtained from the Pennsylvania Department of Environmental Protection (PA-DEP) website for the Office of Environmental Justice [33]. At the time of this analysis the state defined these census tracts as containing greater than or equal to $30 \%$ of the resident population represented as non-white minority and/or greater than or equal to $20 \%$ of the population living below the Federal poverty limit. We also obtained a downloadable Excel file listing each EJ-designated tract and their delineation as meeting the race alone, poverty alone, or race + poverty criteria. Statistical methods used to derive these designations, however, were not detailed, but simply stated as "based on the most current census tract data from the U.S. Census Bureau and the federal guidelines for poverty". This site was recently updated after the preparation of this manuscript and now contains updated EJ designations at the census block group level.

We further sought to validate these data independently in some way. Racial distribution estimates taken from the 2010 decennial census for each tract were used to determine \% non-white minority in each tract. For poverty information, we were compelled to rely on the less accurate American Community Surveys (ACS). To assess the percent poverty in each tract we extracted the estimated total number of people in each tract along with the estimated people living in poverty from 2 different 5-year ACS estimates (2006-2010 and 2009-2013). This time period was chosen to approximate the time of the air monitoring campaign used to develop the exposure model. Coefficients of variations (CV\%) were derived from the +/- error for each tract and expressed as a percent of the estimate. For details on methodology of validation see Supplemental Data. Average CV\% for total population for all tracts were 6.5 and 6.4 and number in poverty were 35.0 and 31.9 for 2006-2010 ACS and 2009-2013, respectively. Inconsistencies between the PA-DEP listing and our independent validation were minor (see below) and we opted to use the original PA-DEP list for our risk-based comparisons.

\section{Integration of EJ and exposure determinations}

In order to assess the relationship between EJ tract and pollutant exposure we first created an exposure continuum by rank ordering all 402 census tracts in Allegheny 

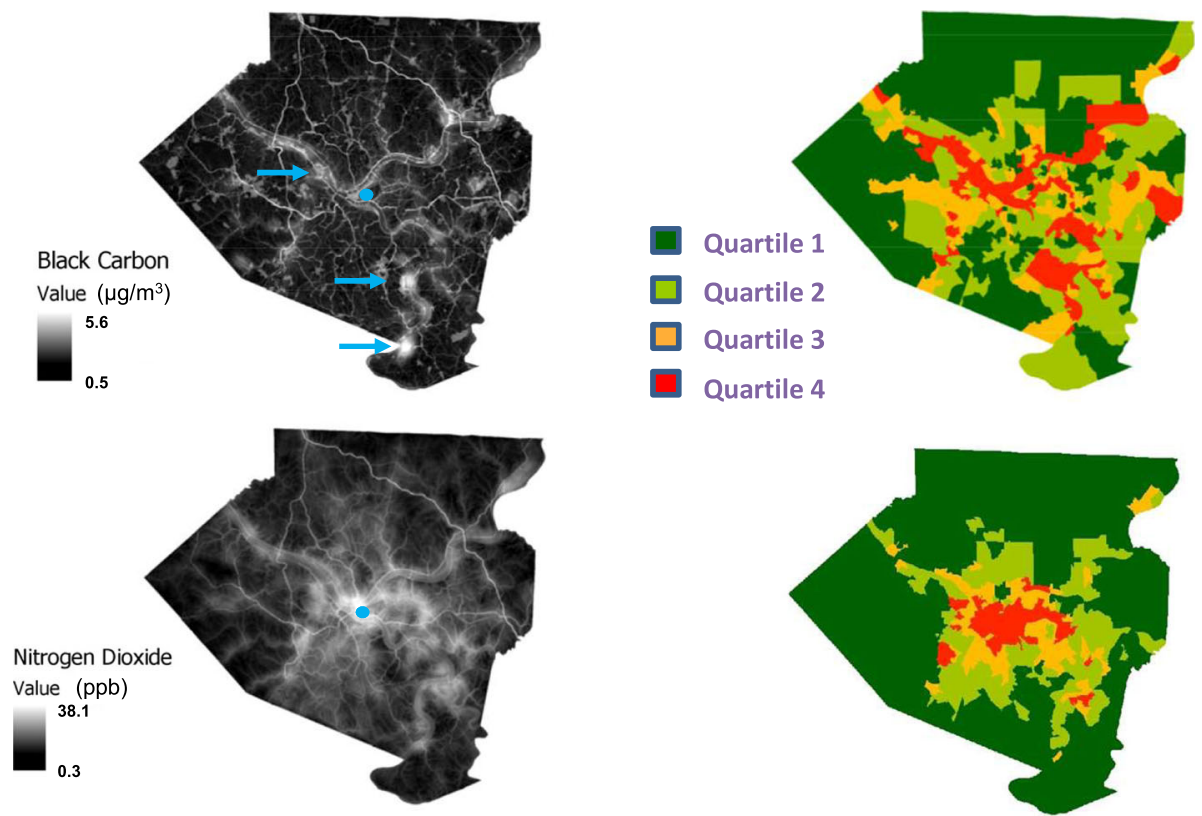

Fig. 1 Exposure maps for black carbon and $\mathrm{NO}_{2}$ in Allegheny County during 2011-2012. Land use regression was applied to model pollutant concentrations as described in Methods. Left panels: represent the estimated distribution of the indicated pollutants as modeled over a grid containing cells sized at $50 \mathrm{~m}$ by $50 \mathrm{~m}$. Pollutant concentrations are depicted over a grey scale with increasing concentrations represented by increased luminosity. The blue dots indicate the location of the Pittsburgh downtown business district, and blue arrows in the BC panel show locations of major industrial sources. An average exposure value for each census tract was calculated as the mean from all cells aggregated within that tract. Right panels show the distribution of census tract exposures divided into 4 quartiles of exposure magnitude where quartile 1 represents the least exposed and quartile 4 represents the highest

County from low to high based on the $\mathrm{NO}_{2}$ and $\mathrm{BC}$ exposure concentration. This distribution was then divided into 4 quartiles of exposure each containing $25 \%$ of the tracts. Specific EJ tracts were then highlighted along the exposure continuum and enumerated in each quartile. In order to determine whether EJ sensitive tracts were differentially distributed across the range of exposures we calculated the incidence ratio of EJ tracts occurring in each of the exposure quadrants $(\mathrm{Q} 2, \mathrm{Q} 3, \mathrm{Q} 4)$ relative to the incidence on the lowest exposed quadrant (Q1). The calculation is similar to a typical relative risk calculation used in an exposure cohort study [34] with substitution of case and control definitions with EJ or non-EJ designation, respectively. Relative incidence of each $\mathrm{Q}_{\mathrm{i}}\left(\mathrm{RI}_{\mathrm{i}}\right)$ was calculated in Eq. 1:

$$
\left.\mathrm{RI}_{\mathrm{i}}=\left[\left(\# E J_{\mathrm{i}}\right) /\left(\# E J_{\mathrm{i}}+\# \text { non-EJ } \mathrm{i}_{\mathrm{i}}\right)\right] /\left[\left(\# E J_{1}\right) /\left(\# E J_{1}+\# \text { non-EJ }\right)_{1}\right)\right]
$$

where 1 denotes lowest exposed quartile, Q1.

Statistically significant difference was taken as nonoverlapping 95\% confidence intervals.

\section{Risk-based modeling of CHD}

For the purposes of developing a risk-based model to estimate disease burden from air pollution we chose a single well-defined health endpoint, coronary heart disease (CHD), for which we could readily obtain a measure for overall county-wide incidence and whose relationship to air pollution exposures had been previously quantified in multiple epidemiological health effect studies [11, 20, 35, 36]. Ischemic coronary heart disease (CHD) deaths were identified by cause of death on death certificates and hospitalizations were defined by ICD codes in hospital records (ICD9, 410-414 and 429.2 or ICD-10, 120-125) available to the county health department. According to the Allegheny County Health Department, crude coronary heart disease death rate in 2010 for Allegheny County, PA was 187.7 deaths per 100,000 people. Total hospitalizations for CHD over this same time throughout the county was 495 per 100,000 people. These overall risk values of $\mathrm{CHD}$ death $(0.001877)$ and hospitalization (0.00495) obviously contain all components of risk beyond air pollution alone.

We next sought to parse out the components of risk that could be specifically attributed to air pollution. For this we relied on effect estimates provided in the study of Gan et al. [20], who conducted an epidemiological study examining the relationship of traffic-related pollutants to CHD hospitalization and mortality in Vancouver (BC, Canada). These authors developed specific quantitative effect estimates relating disease occurrence to long-term 
exposure to each specific pollutant after correcting for demographic variables (age, sex, comorbidity, and socioeconomic status) and levels of co-pollutants. They estimated a 3 and 6\% increase in CHD hospitalization and mortality, respectively for every $0.752 \mu \mathrm{g} / \mathrm{m}^{3}$ increment in $\mathrm{BC}$ exposure. For $\mathrm{NO}_{2}$, they calculated a $3 \%$ increase in CHD death for every $8.4 \mu \mathrm{g} / \mathrm{m}^{3}$ (4.47 ppb) increment in $\mathrm{NO}_{2}$. While a positive exposure-response relationship for hospitalization was evident after correction for demographic variables, it was not observed after correction for co-pollutants, so was not included for the present analysis.

To specifically address the air pollutant component of CHD risk in Allegheny County, we applied Gan et al.'s effect estimates [20] as follows. First, the overall county-wide risk of CHD death or hospitalization was arbitrarily assigned to the population-based midpoint exposure value of the county's exposure continuum for $\mathrm{BC}$ or $\mathrm{NO}_{2}$ (i.e. the $\mathrm{BC}$ or $\mathrm{NO}_{2}$ exposure value of that census tract located at the point where $50 \%$ of the total population is at or above that value and $50 \%$ of the population is at or below that value). This relates the overall risk of disease to a midpoint county-wide standardized exposure value. The overall risk for each ascending and descending tract was then adjusted incrementally by the effect estimates of Gan et al. [20], applied to differences in exposure of that tract relative to midpoint. Therefore, the difference in risk within each tract relative to the population midpoint reference represents the augmentation or attenuation of risk arising from progressively higher and lower levels, respectively, of exposure relative to a countywide average. We then added the inverse of the negative risk in the lowest exposed tract as a constant to all other tracts. Thus, all resulting risk estimates are positive and expressed relative to the exposure in the lowest exposed tract. These risk values were then applied to the total census population of each tract to obtain a populationadjusted estimate of disease burden in each tract. A mathematical representation of the calculations described above is provided in the Supplemental Material (Equation S1). Risk values for each tract were summarized according to EJ or non-EJ designation, were found to not follow a normal distribution (D'Agostino \& Pearson omnibus normality test), and then compared between each class using a nonparametric Mann-Whitney U-test.

\section{Results}

Figure 1 shows the geographic distribution of $\mathrm{NO}_{2}$ and $\mathrm{BC}$ exposures across Allegheny County as estimated by the land-use regression modeling. At the highly resolved $50 \times 50 \mathrm{~m}$ grid scale, discrete high levels of $\mathrm{BC}$ can be seen as white thread-like filaments extending throughout the county, which correspond to the major highways and transportation arteries. In addition, areas of high concentration of $\mathrm{BC}$ from major point sources, primarily coke processing and steel production, are also apparent (arrows). Distribution of $\mathrm{NO}_{2}$ appears more diffuse but still shows considerable heterogeneity throughout the county and again roughly tracks the location of major roadways and areas of high traffic density. When averaged at the level of census tracts, $\mathrm{NO}_{2}$ levels are highest in areas located toward the urban center of downtown Pittsburgh and tracts near major roadways and then progressively decrease as one moves toward the suburban margins. Similarly, the highest levels of BC are observed in areas characterized by either high traffic or the location of industrial point sources. Descriptive statistics describing the distribution of $\mathrm{BC}$ and $\mathrm{NO}_{2}$ census tract exposures including mean, median, and range for total and individual quartiles are provided in Tables S1, S2 (Supplementary Data). Quartiles were defined based on ranking along the exposure continuum for each pollutant. (e.g., Q1 contained the $25 \%$ of tracts with the lowest concentration).

Figure 2 shows the correlation between $\mathrm{NO}_{2}$ and $\mathrm{BC}$ exposure estimates between individual census tracts. As expected, there is a positive correlation between these two pollutants whereby higher concentrations of $\mathrm{NO}_{2}$ exposure are, in general, associated with higher concentrations of $\mathrm{BC}$ over the area. Significant variability, however, is apparent with numerous tracts falling far above or below the regression line. Linear regression of the relationship for codependence of these two pollutants on each other only explains approximately $30 \%$ of total variability in the distribution. Spearman's rank correlation coefficient appropriate for non-Gaussian distributions was 0.58 indicative of only a moderate correlation between the two pollutants.

A comparison of EJ tracts designated by PA-DEP and their validation as described in Methods is shown in Tables S3 and S4 (Supplemental Data). PA-DEP listed 136 total EJ tracts, however, we found 134 based on the validation. The PA DEP classification accurately predicted EJ status based on race in every case. However, there were 13 tracts defined by PA-DEP as race alone that met our validation criteria of race and poverty. In addition, validation revealed 3 tracts defined only by race, but PA-DEP designated as race and poverty. Regardless, this difference does not materially change their inclusion as EJ tracts. Validation for poverty using combined 2006-2010 and 20092013 ACS indicated 5 tracts designated as EJ by PA-DEP based on poverty alone were slightly below the $20 \%$ poverty threshold and 3 previously unidentified tracts that met the poverty threshold that were not indicated as EJ by PA-DEP. Note that these last 3 tracts only barely exceed the $20 \%$ threshold. These discrepancies most likely arise from the inherent inaccuracies in the small-sample ACS estimates. Average CVs for the percent poverty estimates based on $+/-$ errors in both total population and number below poverty were approximately $34 \%$ for both ACS surveys. It is not clear which versions of ACS the PA-DEP 


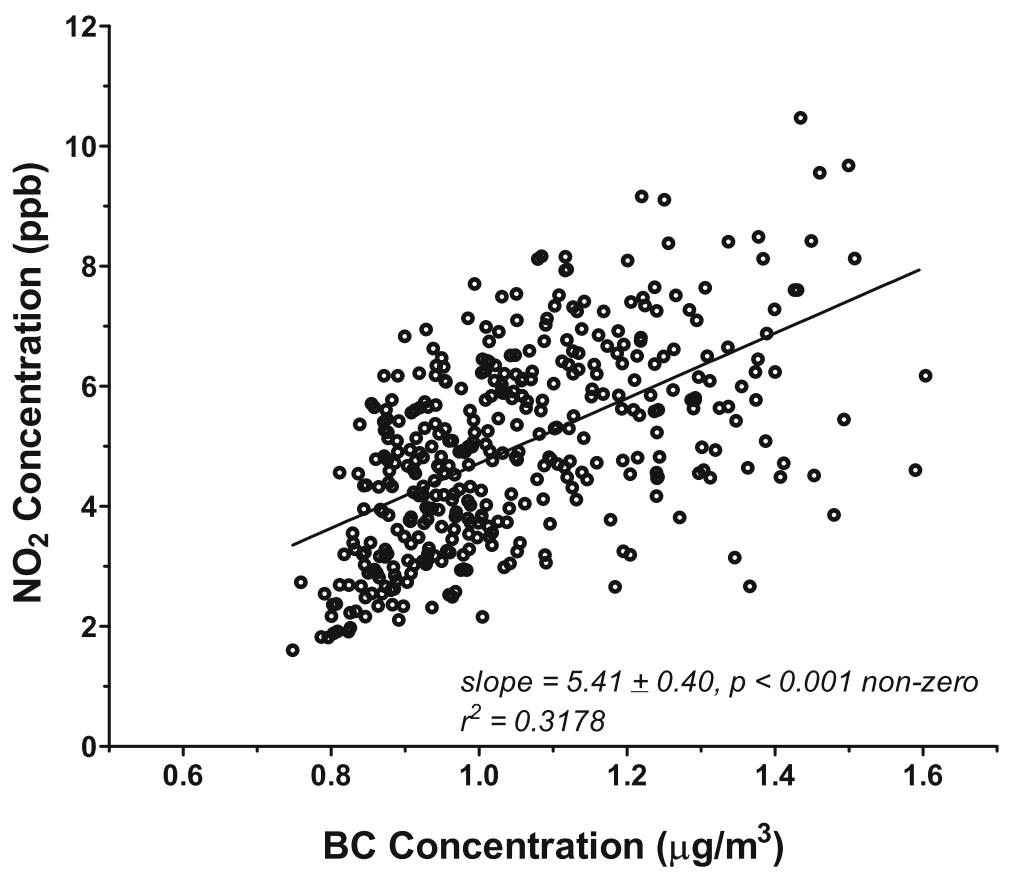

Fig. 2 Correlation of $\mathrm{BC}$ and $\mathrm{NO}_{2}$ levels within Allegheny County census tracts. Exposure estimates for each pollutant were obtained for each census tract as described from the LUR models (Fig. 1). Each point represents a single tract plotted in terms of its modeled $\mathrm{BC}\left(\mu \mathrm{g} / \mathrm{m}^{3}\right)$ and $\mathrm{NO}_{2}$ (ppb) value. Linear regression of the entire dataset indicates a significant positive correlation between each pollutant; however, considerable variability exists around the linear relationship $\left(r^{2}=0.3178\right)$

utilized or whether any thresholds were applied for CVs. While acknowledging these uncertainties we utilized only those EJ tracts listed as such by PA-DEP for further analysis.

Figure 3 shows the exposure continuums for each of the two pollutants. The 402 census tracts are ranked in increasing order based on average exposure estimates obtained from the LUR modeling. The red bars indicate those tracts that meet the criteria to be considered EJ areas. EJ tracts do not appear to be randomly distributed over the range of exposures. Very few EJ tracts are localized in the areas with the lowest exposure estimates, while a preponderance of EJ tracts are skewed towards areas of higher exposure. This is especially prominent for $\mathrm{NO}_{2}$.

We sought to develop a quantitative measure to describe EJ disparities. Each distribution was divided into quartiles (Q1 - Q4) of increasing exposure and the relative occurrence of EJ tracts in increasing quadrants of exposure $(\mathrm{Q} 2-\mathrm{Q} 4)$ relative to the lowest (Q1) was calculated. Table 1 shows that for $\mathrm{BC}, \mathrm{EJ}$ tracts range from 2-fold more abundant in Q2 to almost 4-fold more abundant in Q4 compared to the lowest exposed quartile. This effect is even more pronounced for $\mathrm{NO}_{2}$, where Q2 contains 5.7 times, Q3 contains 8.7 times, and Q4 contains almost 20 times more EJ tracts relative to the first quartile. Thus, there appears to be a differential distribution of EJ tracts towards areas of higher exposure for both the $\mathrm{BC}$ and $\mathrm{NO}_{2}$ pollutants.
Disparities of exposure by race and income are also noted when one considers the population of Allegheny County as a whole. Tables S5 and S6 (Supplemental Data) show total, racial (based on 2010 decennial census) and impoverished (based on average of 2010 and 2013 5-yr ACS estimates) population distributions for the entire county over the various quartiles of exposure for $\mathrm{NO}_{2}$ and $\mathrm{BC}$. There are approximately 1.2 million people residing in Allegheny County of which $81.2 \%$ are white, $18.8 \%$ are non-white minority, and $13.1 \%$ live in poverty. There were progressively fewer total people living in the quartiles of higher exposure compared to lowest. For BC, 34\% of the total population lives in Q1, compared to only $17.3 \%$ in Q4 (Table S5). Intermediate numbers reside in Q2 (27\%) and Q3 (21.7\%). This trend is mirrored by the white majority population of the county. In contrast, the non-white minority population is greater in the higher exposure quartiles, especially for $\mathrm{NO}_{2}$ (Table S6) with $16.5 \%$ in in Q1, 22.1\% in Q2, 25.9\% Q3, and $35.5 \%$ in Q4. Poverty shows a similar trend as race for both $\mathrm{BC}$ and $\mathrm{NO}_{2}$ with even greater gaps between the numbers of people below the poverty line residing in the highest quartiles of exposure compared to the lowest. Figure 4 considers the proportion of nonwhite minority (panel A) and impoverished (panel B) residents that compose each quartile of exposure for $\mathrm{BC}$ and $\mathrm{NO}_{2}$. In all cases, the composition of succeeding higher levels of exposure quartiles demonstrates that the 

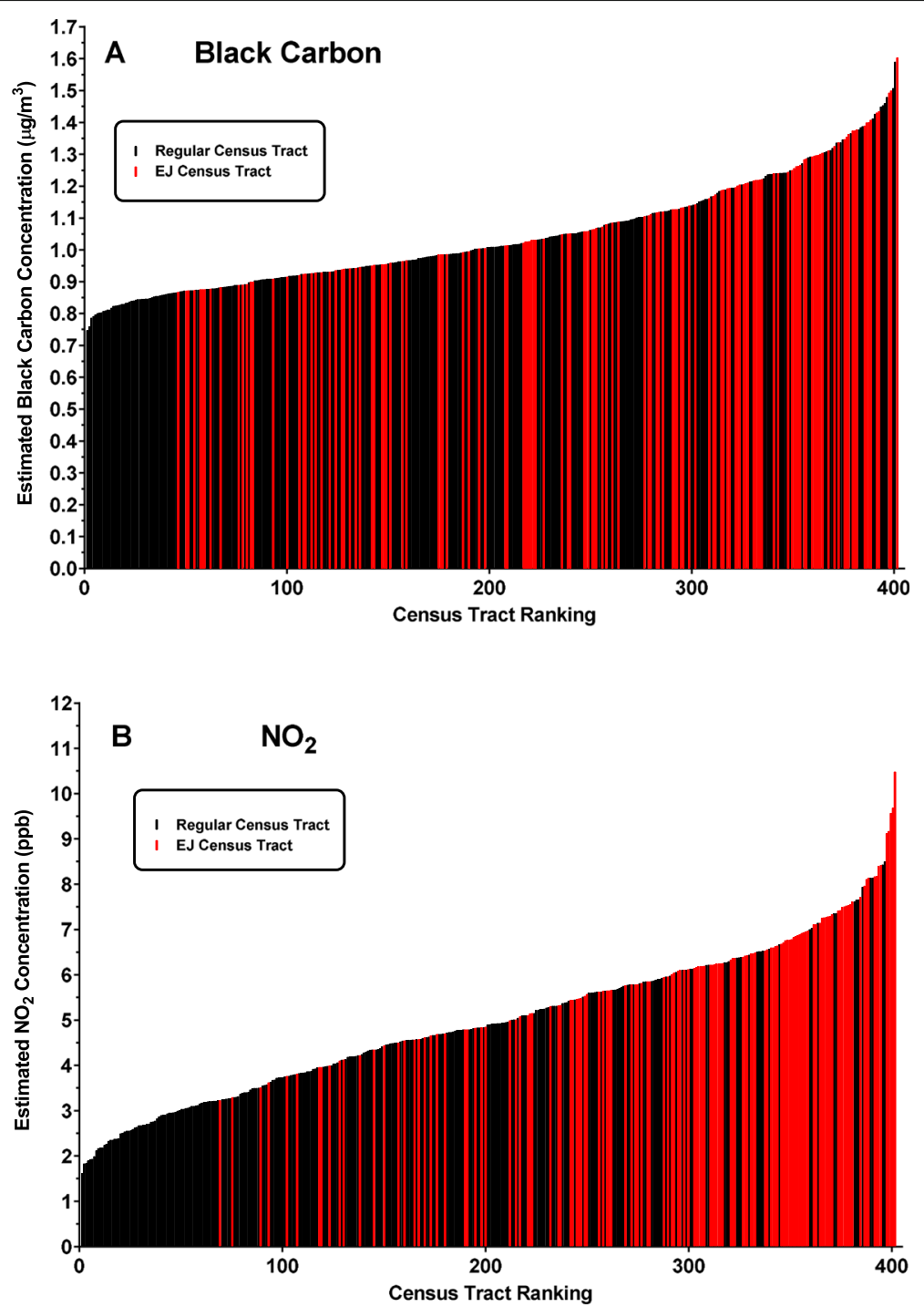

Fig. 3 Distribution of EJ census tracts along the exposure continuum of black carbon (a) and nitrogen dioxide (b) in Allegheny County. Average long-term exposure estimates for each pollutant were derived for each census tract in the county following land-use regression as described in Methods. Based on the resulting exposure metric, tracts are ranked from lowest to highest exposure and those designated as EJ sensitive are displayed in red

percentages of non-white and economically disadvantaged people progressively increases $3-4$ fold over the exposure range.

Next, we sought to develop a model in order to provide a risk-based estimate of disease burden attributed to air pollution within this area. Figure 5 shows a schematic flow-chart of the steps employed in this approach. The example depicted is for CHD mortality and BC exposure. First, we obtained the average death rate for CHD for all of Allegheny County (187.7/100,000 population) from 2010. We arbitrarily assigned this countywide average risk value $(0.001877)$ to the population midpoint value of exposure as a surrogate for an average countywide exposure to each pollutant as described in Methods. Note that this represents the risk of CHD death from all causes and not just air pollution. The risk of CHD death in each tract is then adjusted upward or downward according the increase or decrease in pollutant exposure in each tract relative to this midpoint using the effect estimate of a $6 \%$ change in CHD mortality for every $0.752 \mu \mathrm{g} / \mathrm{m}^{3}$ increment change in $\mathrm{BC}$ described Gan et al. [20]. To estimate the relative pollutant-specific component within overall risk in each tract, the total risk value of the midpoint tract is subtracted from the total risk value in each of the other tracts. This leaves a residual component of risk that represents the estimated $\mathrm{BC}$-specific effect relative to a county-wide average. In order to more appropriately visualize the detrimental effect of pollution over the entire county, we then 
Table 1 Relative incidence of EJ Census Tracts in Allegheny County, PA increase as a function of pollutant exposure

\section{Exposure}

\begin{tabular}{lllll}
\hline & Quartile 1 & Quartile 2 & Quartile 3 & Quartile 4 \\
\hline Black Carbon & 1 & $2.0(1.2-3.6)$ & $2.4(1.4-4.1)$ & $3.6(2.2-5.9)$ \\
$\mathrm{NO}_{2}$ & 1 & $5.7(2.0-15.9)$ & $8.7(3.2-23.5)$ & $18.5(7.1-48.7)$
\end{tabular}

Data represent the fold-increases in the number of tracts meeting the criteria for EJ designation among the approximate 100 tracts represented in each quartile of increasing $\mathrm{BC}$ or $\mathrm{NO}_{2}$ exposure relative to the occurrence of EJ tracts in the lowest exposed quartile. Parentheses represent the $95 \%$ confidence interval for the determination

asked what the pollutant-specific risks would be from pollutant levels in excess of the lowest exposed census tract. For this the BC-specific risks are then expressed relative to that in the lowest tract instead of the midpoint by adding the negative risk in the lowest tract as a constant to the $\mathrm{BC}$-risk in all tracts (panel C). These final risk estimates are then applied to the population residing in each census tract to obtain an estimate of the CHD disease burden posed by pollutant exposure in each census tract (panel D). These can then be summed across the entire county or, specifically in EJ and non-EJ census tracts (as defined by the PA-DEP). Similar steps were employed for hospitalization rates using the appropriate effect estimates. Only CHD mortality was analyzed for $\mathrm{NO}_{2}$ since Gan et al. [20] failed to find a significant association between $\mathrm{NO}_{2}$ exposure and $\mathrm{CHD}$ hospitalization after correcting for co-pollutants.

Figure 6 shows the pollutant- and endpoint-specific risk values calculated for each individual census tract and compared between EJ and non-EJ tracts. In all cases, the average pollutant-dependent risk value was significantly higher for EJ tracts compared to non-EJ tracts. For BC, the risk for CHD mortality and hospitalization in approximately half of the EJ tracts was within the same range of only $25 \%$ of the highest exposed non-EJ tracts. For $\mathrm{NO}_{2}$, nearly $75 \%$ of EJ tracts are equivalent or greater than the highest exposed $25 \%$ of non-EJ tracts.

We estimated that, regarding the county as a whole, $\mathrm{BC}$ and $\mathrm{NO}_{2}$ exposures in excess of that present in the lowest exposed census tract were predicted to cause approximately 49 and 46 deaths, respectively from CHD annually. Together, these numbers represent approximately $4 \%$ of all countywide CHD deaths annually. Figure 6 shows the distribution of these predicted deaths between EJ and non-EJ tracts. With $\mathrm{BC}$ and $\mathrm{NO}_{2}$ it appeared that 38 and $42 \%$, respectively, of the predicted pollutant-related CHD mortality burden was present within EJ sensitive areas (Fig. 7a, b). However, the population of EJ areas represents
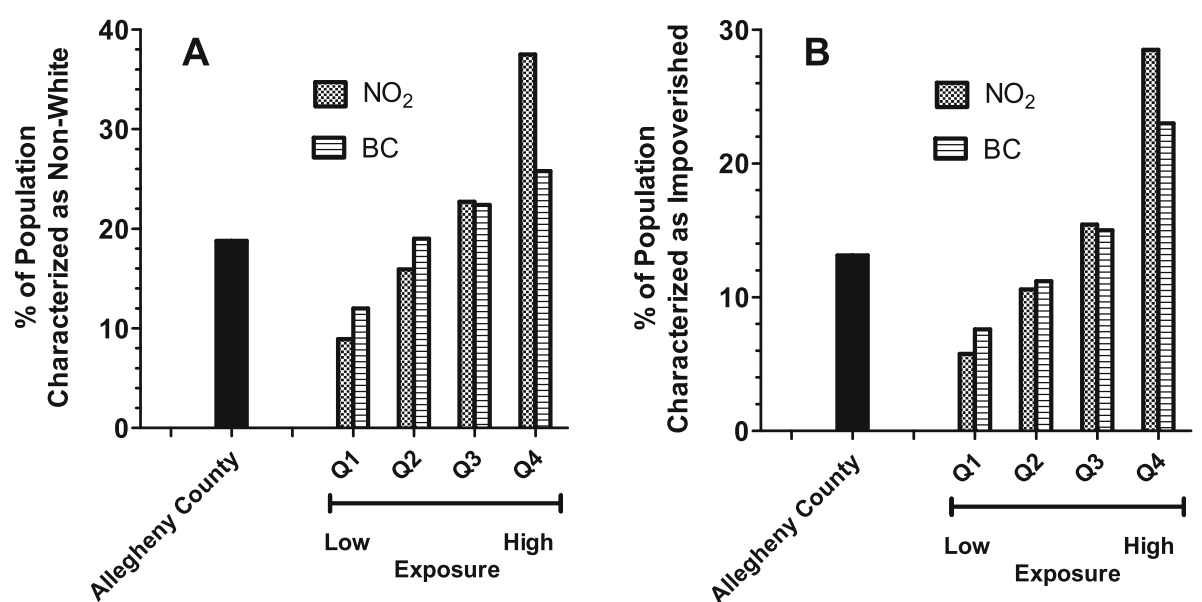

Fig. 4 Percent of residents characterized as racial non-white minority (a) or impoverished (b) in various quartiles of pollutant exposure. Exposure continuums for each pollutant were divided into quartiles as described in Methods. Q1 represents the lowest exposed quartile and Q4 represents the highest. The total population as well as residents characterized as non-white or with incomes below the poverty line was determined for each census tract and then summed within each quartile. Racial minority and poverty were then expressed as a percent of the entire population within each quartile. The percentages of non-white and impoverished residents relative to the entire county population is shown for reference 
A

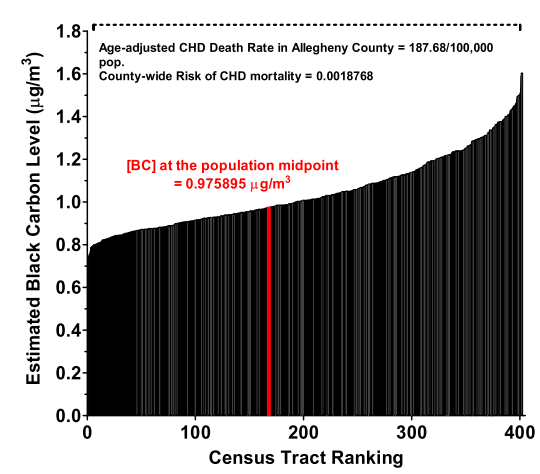

C

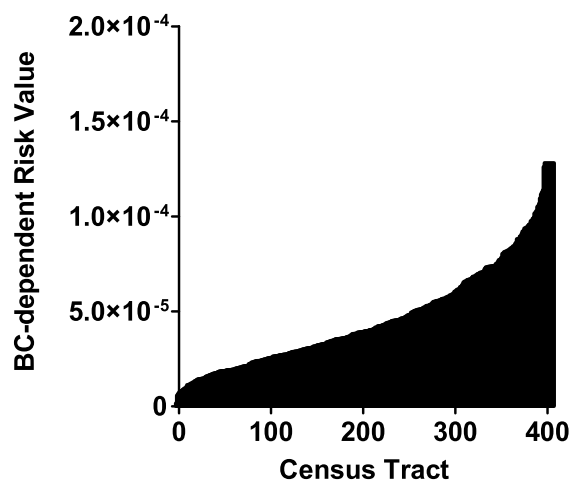

B

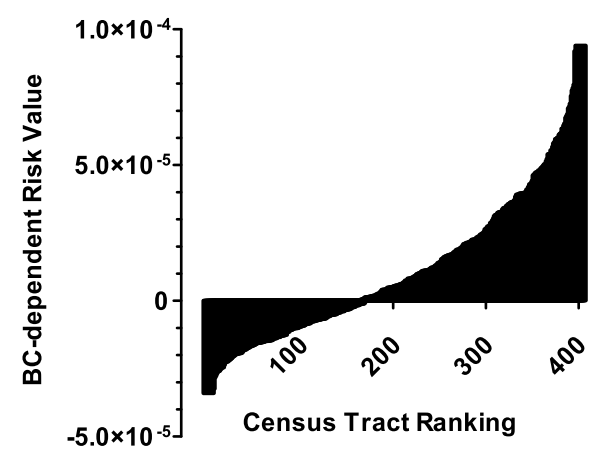

D

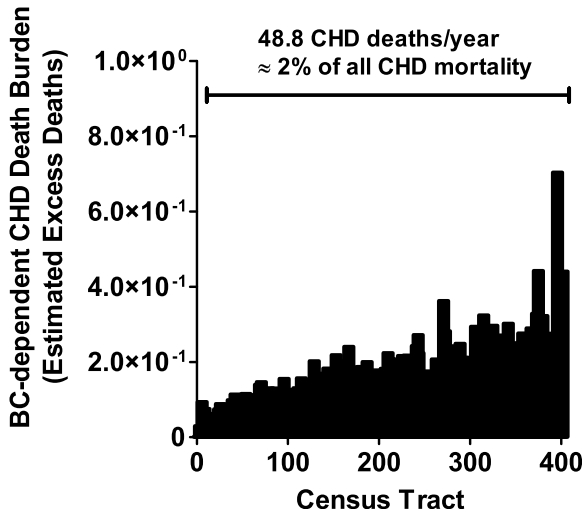

Fig. 5 Steps used to develop a risk-based model of CHD burden from black carbon. a shows the exposure continuum for black carbon over all census tracts as described above. As a starting point, the overall age-adjusted average death rate for CHD for the entire county was arbitrarily assigned to the exposure metric for BC $\left(0.975895 \mu \mathrm{g} / \mathrm{m}^{3}\right)$ corresponding to the census tract that marks the population midpoint (ie., $50 \%$ of population lies below and $50 \%$ of population lies above this point). The overall risk of CHD death was then adjusted upward or downward based on the BC increment in each preceding and succeeding tract based on the BC effect estimate for CHD mortality reported by Gan et al. [20]. $\mathbf{b}$ shows the $\mathrm{BC}$-dependent contributions to risk relative to the $\mathrm{BC}$ exposure present in the mid-population census tract. $\mathbf{c}$ expresses the BCdependent risk value relative to the $\mathrm{BC}$ metric contained in the lowest exposed census tract. $\mathbf{d}$ shows the overall predicted $\mathrm{BC}$-dependent $\mathrm{CHD}$ death burden in each tract by applying the risk values shown in panel $\mathrm{C}$ to the population of each census tract. When the disease burden is summed across all census tracts in the county, the model estimates a total of 48.8 CHD deaths arising from BC in excess of that present in the lowest exposed census tract, or $2 \%$ of the entire CHD deaths measured in the county

only $27 \%$ of the total population in the county (Fig. 7c). Black carbon was associated with approximately 64 predicted excess hospitalizations for CHD in the county per year (approximately $1 \%$ of the total), and again about $40 \%$ of those were represented within EJ tracts (data not shown).

\section{Discussion}

Advocates of environmental justice have long appreciated the fact that environmental exposures are frequently increased amongst people of low socio-economic status and minority people of color, and by extension, they are likely to suffer greater burden of adverse health effects. Our data show that in Allegheny County, EJ sensitive areas are more numerous in areas of higher exposure and bear a disproportionate amount of risk of $\mathrm{CHD}$ from air pollution compared to non-EJ areas. These groups frequently are not adequately informed as to the nature of the environmental hazards present in their communities, lack an effective mechanism to voice concerns or advocate for change, and lack resources to move or otherwise improve their situation. While environmental health disparities have long been recognized and attempts made to address this at the policy level, inequities remain. Clark et al. recently compared $\mathrm{NO}_{2}$ exposures across the entire US for the years 2000 and 2010 based on race-ethnicity and socioeconomic status [25]. While significant reductions on $\mathrm{NO}_{2}$ were observed across all areas and all groups over this time, marked disparities by race and income remained. Overall, the nonwhite to white disparity declined from $5.0 \mathrm{ppb}$ in 2000 to 2.9 in 2010; however, on a relative basis, non-whites remained 37\% more-exposed than whites in 2010 

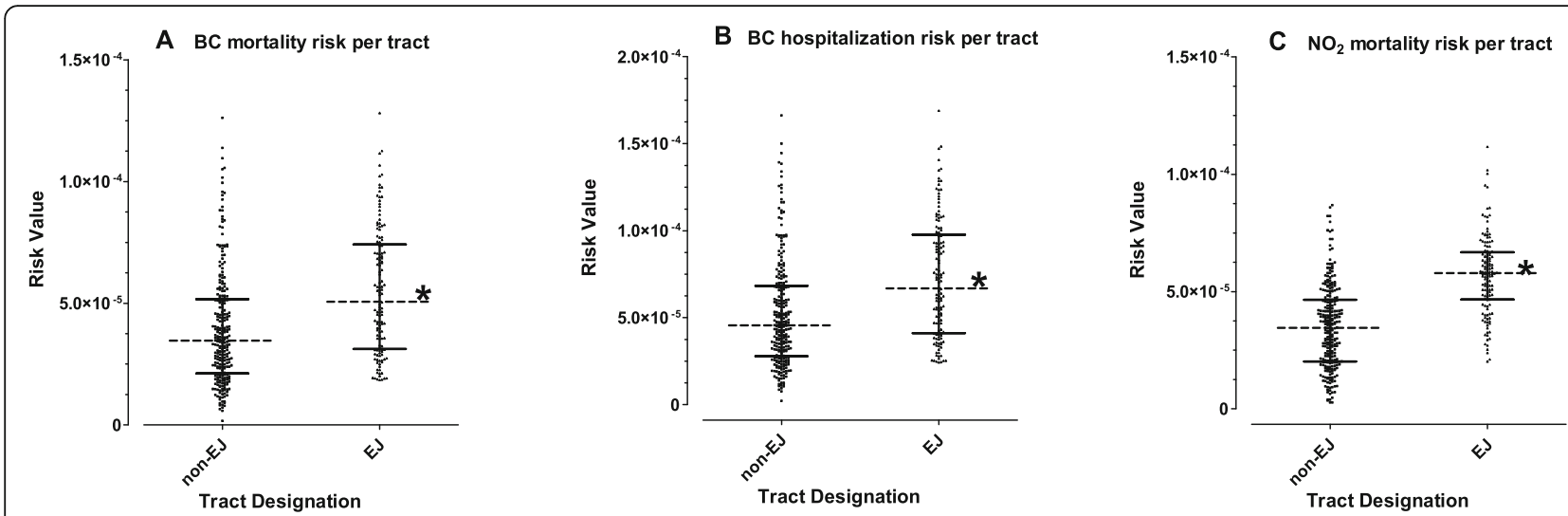

Fig. 6 Comparison of pollutant-dependent CHD mortality and hospitalization risks between EJ and non-EJ census tracts in Allegheny County. The component of disease risk attributed to $\mathrm{BC}$ or $\mathrm{NO}_{2}$ was calculated for each census tract as described in Fig. 5. Data shows the distribution of all individual risk values compared between non-EJ $(n=265)$ and EJ $(n=136)$ tracts. Dotted lines represent the median and solid lines represent the interquartile range. Asterisks denote statistically significant difference between EJ and non-EJ tracts by Mann-Whitney U-test $(p<0.001)$

compared to $40 \%$ in 2000. In fact, $\mathrm{PM}_{2.5}$ and $\mathrm{NO}_{2}$ exposure inequities may have actually broadened in some areas [37]. Thus, policies typified by the Clean Air Act to reduce air pollution over the entire population do little to reduce social and economic disparities.

Clark et al. found stronger disparities based on race and ethnicity than on income [25]. Since most of the EJ tracts in Allegheny County (49\%) are defined by both parameters of $30 \%$ minority and $20 \%$ poverty, it was difficult for us to address the relative role of each alone. We did, however, compare all PA-DEP defined EJ tracts that included the race factor (regardless of income) to those defined by income (regardless of race) and found stronger associations between race and higher exposure than we did for income (data not shown).

Understanding the sources of these exposures will be important to develop and implement strategies targeted towards reducing exposures amongst EJ communities and normalize the disparities throughout the county. $\mathrm{NO}_{2}$ is most often considered a traffic-related pollutant, while $\mathrm{BC}$ contains significant contributions from both mobile and point sources. EJ communities are, in general, subjected to greater traffic-related pollution compared to other areas. The early transportation policies of the 1970's were characterized by rapid expansion of high-density freeways and thoroughfares that transect or encircle major urban centers [38, 39]. Such construction was geared to meet the demands of urban sprawl with delivery of goods and services to and from large urban centers and long-distance commuting of workers, but gave rise to significant increases in diesel truck traffic as well as high-number of single-occupancy vehicles. Such policies frequently failed to consider the impact on communities closest to their construction, which are often composed of those groups least able to afford the suburban migration predominated by affluent whites. Traffic- related air pollutants can remain elevated up to 500 $1000 \mathrm{~m}$ from the roadway [40, 41]. Rowangould found that racial minorities and low-income households were more likely to live near high traffic roadways than the general population [42].

The Q4 areas for both $\mathrm{BC}$ and $\mathrm{NO}_{2}$ shown in Fig. 1, however, are a mix of both high traffic and industriallyimpacted areas. Recently, Mikati et al. showed disparities by race and poverty status regarding proximity to major industrial point sources of $\mathrm{PM}_{2.5}$ [43]. Thus, it is likely that industrial emissions also contribute significantly to the disparities in exposure seen here. In addition, Allegheny County geography is predominated by multiple large river valleys in which major transportation arteries (including rail and barge traffic), major industrial point sources, and socio-economically disadvantaged neighborhoods are colocalized in low-lying regions prone to pollution trapping.

Although there is some co-localization of the two pollutants considered here, for the overall estimation of CHD disease burden we considered $\mathrm{NO}_{2}$ and $\mathrm{BC}$ as independent factors whose combined effects were likely additive. While direct effects of $\mathrm{PM}_{2.5}$ on a variety of health endpoints has been well established, it appears that $\mathrm{NO}_{2}$ also has effects independent of other copollutants [44]. We applied risk estimates for each that had been previously corrected for co-pollutant contributions [20]. Moreover, in our exposure distributions we observed considerable departure in the co-dependence of each pollutant (Fig. 2) with numerous census tracts showing an elevation of one but not the other pollutant leaving nearly $3 / 4$ of the variation in each unexplained by co-dependence of the other pollutant. Thus, the overall burden of disease needs to consider the totality of independent contributions from multiple pollutants.

Our model also assumes a linear dose-effect relationship over the range of pollutant concentrations expressed here, 


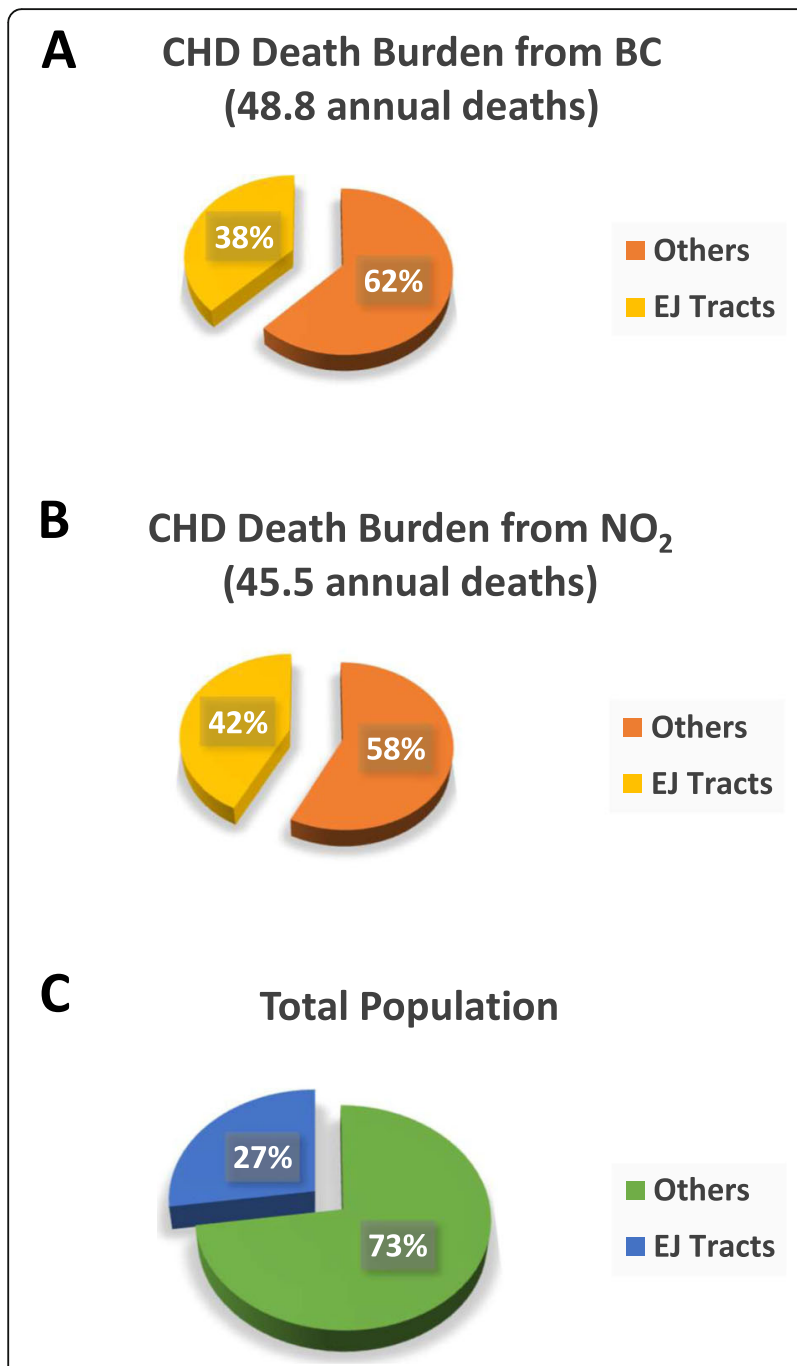

Fig. 7 Risk-based estimate of CHD burden in EJ and non-EJ tracts in Allegheny County. Predicted annual cases of $\mathrm{CHD}$ mortality resulting from $\mathrm{BC}$ and $\mathrm{NO}_{2}$ exposure were calculated in each census tract in Allegheny County based on the pollutant exposure estimates, riskbased modelling, and total populations as described in Methods and Fig. 5. Overall, $\mathrm{BC}$ and $\mathrm{NO}_{2}$ were predicted to account for 49 and $46 \mathrm{CHD}$ deaths, respectively, within the entire county. When divided into those estimated to occur in EJ tracts vs non-EJ regions, approximately $40 \%$ were represented in EJ tracts (38\% for BC, a, $42 \%$ for $\mathrm{NO}_{2}, \mathbf{b}$ ) despite the fact that the population of EJ tracts represents only $27 \%$ of the entire county population (c)

although there may be significant departure from linearity at extremes of exposures experienced in other parts of the world [45]. Of note is the observation that a positive association between adverse effects and pollutant concentrations below ambient standard has been demonstrated [46], especially for the elderly, and scientific consensus holds that no threshold for such adverse effects has been demonstrated. Predicting the effect estimate at very low pollutant levels may be controversial; however, we modeled our disease burden calculations relative to the exposure in the lowest census tract, and not to the elimination of pollutant entirely from the ambient environment.

Lacking any more definitive quantitative dose-response function applicable to long-range exposures over this relatively narrow exposure range, we feel application of a linear model is a reasonable initial approach. First, the rise in health of effects of BC-dependent hospitalization and mortality and $\mathrm{NO}_{2}$-dependent mortality appear linear over the quintiles of exposure measured in Gan et al. [20]. Moreover, while studies measuring $\mathrm{PM}_{2.5}[47,48]$ show complex biphasic dose-responses characterized by steeper linear dose-response at low doses and attenuation of effect at higher dose extremes, the relative narrow range of $\mathrm{BC}$ concentrations encountered in both Gan et al. [20] and our study would likely fall in the steeper portions of the $\mathrm{PM}_{2.5}$ curves that approximate linearity. Bai et al. [49] present a dose-response for $\mathrm{NO}_{2}$ and myocardial infarction that approximates linearity between 2 and $10 \mathrm{ppb}$ and then decreases its slope as doses exceed $10 \mathrm{pbb}$. If the effect estimate of Gan et al. [20], is over-represented from the higher part of this curve, that could lead to an underestimation of $\mathrm{NO}_{2}$ burden estimated here, as Allegheny County $\mathrm{NO}_{2}$ concentrations actually would have greater representation from the steeper part of that curve than those of Gan et al. [20]. The fact that the $\mathrm{BC}$ had a greater impact on CHD mortality ( $2 \%$ of total) compared to CHD hospitalization ( $1 \%$ of total) within the context of greater number overall hospitalizations compared to deaths was somewhat surprising. This arises from the stronger effect estimates for mortality compared to hospitalization derived by Gan et al. [20]. In fact, $\mathrm{NO}_{2}$ failed to have a significant effect on hospitalization in that study despite having a positive impact on mortality. One explanation may be that the untoward cardio-vascular effects of air pollution may be more significant in older individuals or those with severe pre-existing disease where triggering an adverse event by pollutant exposure may have a disproportionate lethal effect compared to those with early, often subclinical, stages of disease. Future health effect studies should take age, pre-existing conditions, and disease stage and severity into consideration when possible to address how these factors may modify the effect of air pollution. In addition, we used baseline CHD mortality and hospitalization rates representative of the entire county population. It might be that additional risk factors in racial minorities and the poor may inflate the overall rate of disease in these groups and lead to an underestimation of EJ disparity in disease burden reported here.

The overall precision of calculating disease burdens also depends on validity of LUR models. First, the exposure estimates reflect projections of long-term average exposure concentrations, hence they ignore short-term fluctuations in concentrations that may also play a role in initiating untoward cardiovascular events [18]. Our 
LUR model incorporating mobile source plume analysis and mobile sampling may improve model application to traffic-related pollutants, but may underestimate the contribution from fixed point sources [50]. Hence, the estimated overall effect of $\mathrm{BC}$ may under-represent those adverse effects arising from industrial $\mathrm{BC}$ emissions from such facilities as coke and steel plants.

Some uncertainty in our risk estimate also arises with the use of effect estimates derived from a single study. Surveying several meta-analyses $[28,51]$ yielded no additional studies providing suitable effect estimates corresponding to long-term exposure specifically for $\mathrm{BC}$ and the CHD endpoint. More information was available from a similar survey of $\mathrm{NO}_{2}$ studies [27]. The mean hazard ratio of 15 studies examining cardiovascular mortality and $\mathrm{NO}_{2}$ collected in the meta-analyses by Atkinson et al. [27] was $1.03 / 10 \mu \mathrm{g} / \mathrm{m}^{3}$ and fell within a 95\% confidence interval of 1.02 and 1.05. Applying these lower and upper bounds for $\mathrm{NO}_{2}$-dependent $\mathrm{CHD}$ mortality to our risk model predicts a range of from 25 to 63 excess deaths per year compared to our single calculation of 46 deaths based on the single effect estimate of Gan et al. [20].

Another limitation is that the effect estimates were drawn from an analysis [20] not conducted within the same geographic area as Allegheny County. Although both Vancouver and Pittsburgh are urban centers of moderate size, differences in pollution sources and other factors may mean that actual concentration-response estimates may not be identical in each locale. In comparing the estimated pollutant exposures between our study and those of Gan et al. [20] we noted similar mean values for BC of 1.19 and $1.05 \mu \mathrm{g} / \mathrm{m}^{3}$ for Vancouver and Allegheny County, respectively, although the range of values in Vancouver is greater as evidenced by an IQR of $0.75 \mu \mathrm{g} / \mathrm{m}^{3}$ compared to only $0.22 \mu \mathrm{g} / \mathrm{m}^{3}$ in our study. Greater differences in $\mathrm{NO}_{2}$ were observed between both studies. Mean $\mathrm{NO}_{2}$ in Allegheny county was $4.96 \mathrm{ppb}$ but over 3-fold higher (17.7 ppb) in Vancouver. Again greater variation is seen in Vancouver with a 2-fold greater IQR (4.47 ppb) compared to Allegheny County $(2.47 \mathrm{ppb})$. The reasons for this are beyond the scope of this discussion but may reflect differences in modeling parameters (residential points vs. census tracts), different sampling periods (late 1990s vs. 2010), and differences in population density, study area size, and pollution sources.

Lastly, it should be pointed out that variables derived from ACS data can contain significant uncertainty based on rather large $\mathrm{CV} \%$ in some areas. We chose to retain the PA-DEP designations since they are the most applicable to policy decisions at the regulatory level, however, the statistical methods applied in their use of ACS data are not available. We have shown that the choice of various ACS datasets can influence some EJ determinations especially regarding income. This variance however likely makes little difference in our results here. First, all
EJ tracts characterized by race and poverty, would still meet the EJ definition by race regardless of what actual percent poverty was. By comparing the PA-DEP listing to our ACS analysis we find only a net under-counting of 2 tracts. This small percentage of total would have little impact in our estimate of EJ incidence within exposure quartiles or overall burden of disease within the population. Nonetheless, depending on the purpose of the research and for conducting future sensitivity analyses researchers may consider applying various arbitrary $\mathrm{CV} \%$ thresholds for flagging potentially unreliable data $[52,53]$. However, it should be pointed that higher $\mathrm{CV} \% \mathrm{~s}$ are frequently are encountered in low income, minority, and urban neighborhoods [54] and a systematic exclusion of these data could itself bias the outcome.

\section{Conclusion}

Our study provides a useful tool by which communities can assess the potential impact of air pollution once provided with an adequate representation of long-term pollutant exposure on a highly-resolved spatial scale. Of course the ability to apply this model depends on access to a suitable air pollution exposure model with high spatial resolution for the area of concern. Publicallyavailable datasets for certain pollutants are becoming increasingly available. Advances in satellite imaging offer increasing geospatial resolution for measuring certain pollutants over large areas. Widespread deployment of low-cost air sensor networks in communities could be used in conjunction with land use regression modeling to construct similar pollutant maps to ours with minimal technical expertise once criteria of instrument reliability and sensitivity are established. Use of a risk-based model allows a timely estimate of the health burden as well as temporal tracking of the potential impacts of mitigation strategies when before and after exposure estimates are available. It will, however, be important to validate the risk-based model using historical or prospective disease data in future studies. Also, a quantitative measure of EJ disparities as employed here is useful to be able to compare different communities, as well as track progress in various corrective public policies. It is important to state that our risk-based estimates presented here refer only to a single disease, namely CHD. Since these same air pollutants have been associated with numerous other serious diseases, many with lethal outcomes, it should be noted that the overall impact of air pollution in this study area is likely much greater than that suggested by the limited analysis here. Future work can now be undertaken to estimate the impact of air pollution on other disease outcomes using our risk-based model and exposure estimates in conjunction with quantitative effect estimates for other diseases available in existing or forthcoming health outcome studies. 


\section{Supplementary information}

Supplementary information accompanies this paper at https://doi.org/10. 1186/s12940-020-00584-Z.

\section{Additional file 1.}

\section{Abbreviations}

BC: Black Carbon; CHD: Coronary Heart Disease; EJ: Environmental Justice; LUR: Land Use Regression; $\mathrm{NO}_{2}$ : Nitrogen Dioxide; PA DEP: Pennsylvania Department of Environmental Protection; PA: Pennsylvania; PM: Particulate Matter; US EPA: United States Environmental Protection Agency

\section{Acknowledgements}

The authors would like to thank Devon McHugh Descutner for proof-reading and providing editorial comments.

\section{Authors' contributions}

AAP conducted the LUR analysis and geospatial mapping of black carbon and $\mathrm{NO}_{2}$ pollutants. EMJ extracted the relevant census data and conducted the analyses relating pollutant exposure to EJ tract areas, and applied the risk-based model to calculate tract-specific disease burden. EMJ was also a major contributor to writing multiple sections of the manuscript. LLB provided countywide CHD mortality and morbidity statistics on which to base the risk-based model, insight in mapping EJ areas and assisted in the preparation of the manuscript. JPF conceptualized and oversaw the entire project, as well as, prepared the finalized version of the manuscript. All authors have read and approved the final manuscript.

\section{Funding}

This work was funded in part by The Heinz Endowments, (grant numbers E3977, E4820, E0678, C2940, and E0144). AAP acknowledges Assistance Agreement No. RD83587301 awarded by the U.S. Environmental Protection Agency. This publication was developed as part of the Center for Clean Air Climate Solutions (CACES), which was supported under Assistance Agreement No. R835873 awarded by the U.S. Environmental Protection Agency. It has not been formally reviewed by EPA. The views expressed in this document are solely those of authors and do not necessarily reflect those of the Agency. EPA does not endorse any products or commercial services mentioned in this publication.

\section{Availability of data and materials}

Population and demographic data for census tracts contained in Allegheny County are publically available and accessible through the U.S. Census Bureau (Census.gov). The datasets used for the LUR modeling of pollutant exposure are available from the corresponding author on reasonable request.

\section{Ethics approval and consent to participate}

Not applicable.

\section{Consent for publication}

Not applicable.

\section{Competing interests}

The authors declare that they have no competing interests.

\section{Author details}

${ }^{1}$ Center for Healthy Environments \& Communities, Department of Environmental \& Occupational Health, University of Pittsburgh Graduate School of Public Health, PUBHL-4132, 130 DeSoto Street Pittsburgh, Pittsburgh, PA 15261, USA. ${ }^{2}$ Allegheny County Health Department, Pittsburgh, PA, USA. ${ }^{3}$ Center for Atmospheric Particle Studies, Department of Mechanical Engineering, Carnegie Mellon University, Pittsburgh, PA, USA.
Received: 1 July 2019 Accepted: 26 February 2020

Published online: 16 March 2020

\section{References}

1. Dockery DW, Pope CA Jr, Xu X, Spengler JD, Ware JH, Fay ME, Ferris BG Jr, Speizer FE. An association between air pollution and mortality in six U.S. cities. N Engl J Med. 1993:329(24):1753-9.

2. Laden F, Neas LM, Dockery DW, Schwartz J. Association of fine particulate matter from different sources with daily mortality in six U.S. cities. Environ Health Perspect. 2000;108(10):941-7.

3. Byers N, Ritchey M, Vaidyanathan A, Brandt AJ, Yip F. Short-term effects of ambient air pollutants on asthma-related emergency department visits in Indianapolis, Indiana, 2007-2011. J Asthma. 2016:533(3):245-52.

4. Gan WQ, FitzGerald JM, Carlsten C, Sadatsafavi M, Brauer M. Associations of ambient air pollution with chronic obstructive pulmonary disease hospitalization and mortality. Am J Respir Crit Care Med. 2013;187(7):721-7.

5. Takenoue Y, Kaneko T, Miyamae T, Mori M, Yokota S. Influence of outdoor $\mathrm{NO}_{2}$ exposure on asthma in childhood; meta-analysis. Pediatr Int. 2012;56(6): 762-9.

6. Brauer M, Lencar C, Tamburic L, Koehoorn M, Demers PA, Karr C. A cohort study of traffic-related air pollution impacts on birth outcomes. Environ Health Perspect. 2008:116(5):680-6.

7. Lim H, Kwon HJ, Lim JA, Choi JH, Ha M, Hwang SS, Choi WJ. Short-term effect of fine particulate matter on children's hospital admissions and emergency department visits for asthma: a systematic review and metaanalysis. J Prev Med Public Health. 2016:49(4):205-19.

8. Mann JK, Tager IB, Lurmann F, Segal M, Quesenberry CP Jr, Lugg MM, Shan J, Van Den Eeden SK. Air pollution and hospital admissions for ischemic heart disease in persons with congestive heart failure or arrhythmia. Environ Health Perspect. 2002:110(12):1247-52.

9. Peters A, Dockery DW, Muller JE, Mittleman MA. Increased particulate air pollution and the triggering of myocardial infarction. Circulation. 2001; 103(23):2810-5.

10. Pope CA 3rd., Turner MC, Burnett RT, Jerrett M, Gapstur SM, Diver WR, Krewski D, Brook RD. Relationships between fine particulate air pollution, cardiometabolic disorders, and cardiovascular mortality. Circ Res. 2015; 116(1):108-15.

11. Pope CA 3rd., Burnett R, Thurston GD, Thun M, Calle EE, Krewski D, Godleski J. Cardiovascular mortality and long-term exposure to particulate matter polution: epidemiological evidence of general pathophysiological pathways of disease. Circulation. 2004:109(1):71-7.

12. Puett RC, Schwartz J, Hart JE, Yanosky JD, Suh H, Paciorek CJ, Neas LM, Laden F. Chronic particulate exposure, mortality, and coronary heart disease in the Nurses' health study. Am J Epidemiol. 2008;168(10):1161-8.

13. Michanowicz D, Ferrar K, Malone S, Kelso M, Kriesky J, Fabisiak JP. PRETA Air: hazardous air pollutants. In: Pittsburgh Regional Environmental Threats Analysis (PRETA) Report. Pittsburgh: University of Pittsburgh Graduate School of Public Health Center for Health Environments and Communities; 2013. http://www.chec.pitt.edu/documents/PRETA/CHEC\%20PRETA\%2 OHAPs\%20Report.pdf. Accessed 24 Oct 2019

14. Michanowicz D, Malone S, Ferrar K, Kelso BA, Clougherty J, Kiesky J, Fabisiak JP. PRETA air: particulate matter. In: Pittsburgh Regional Environmental Threat Analysis (PRETA) Report. Pittsburgh: University of Pittsburgh Graduate School of Public Health Center for Healthy Environments and Communities; 2012. http://www.chec.pitt.edu/documents/PRETA/PRETA_PM.pdf. Accessed 24 Oct 2019.

15. Michanowicz D, Malone S, Ferrar K, Kelso M, Christen C, Volz CD, Goldstein BD. PRETA air: ozone. In: Pittsburgh Regioinal Environmental Threats Analysis (PRETA) Report. Pittsburgh: University of Pittsburgh Graduate School of Public Health Center for Healthy Environments and Communities; 2011. http://www.chec.pitt.edu/documents/PRETA/CHEC\%20PRETA\%2 0Ozone\%20Report.pdf. Accessed 24 Oct 2019

16. Bureau of Air Quality. PA Department of Environmental Protection: Attainment Status by Principal Pollutants. Harrisburg; 2016. http://www.dep. pa.gov/Business/Air/BAQ/Regulations/Pages/Attainment-Status.aspx. Accessed 13 Feb 2018

17. Bureau of Air Quality. PA Department of Environmental Protection: Final designation recommendations for the 2015 eight-hour ozone national ambient air quality standards. Harrisburg: 2016. http://files.dep.state.pa.us/ Air/AirQuality/AQPortalFiles/Regulations\%20and\%20Clean\%20Air\%20Plans/ 
attain/Ozonedes/02_2015_NAAQS_Ozone_Final_Designation_ Recommendations_Final_Oct_2016.pdf. Accessed 24 Oct 2019.

18. Di Q, Dai L, Wang Y, Zanobetti A, Choirat C, Schwartz JD, Dominici F. Association of short-term exposure to air pollution with mortality in older adults. JAMA. 2017;318(24):2446-56.

19. Shi L, Zanobetti A, Kloog I, Coull BA, Koutrakis P, Melly SJ, Schwartz JD. Lowconcentration $\mathrm{PM}_{2.5}$ and mortality: estimating acute and chronic effects in a population-based study. Environ Health Perspect. 2016;124(1):46-52.

20. Gan WQ, Koehoorn M, Davies HW, Demers PA, Tamburic L, Brauer M. Long-term exposure to traffic-related air pollution and the risk of coronary heart disease hospitalization and mortality. Environ Health Perspect. 2011;119(4):501-7.

21. Erqou S, Clougherty JE, Olafiranye O, Magnani JW, Aiyer A, Tripathy S, Kinnee E, Kip KE, Reis SE. Particulate matter air pollution and racial differences in cardiovascular disease risk. Arterioscler Thromb Vasc Biol. 2018;38(4):935-42.

22. Burnett R, Chen H, Szyskowicz M, Fann N, Hubbell B, Pope CA 3rd., Apte JS, Brauer M, Cohen A, Weichenthal S, et al. Global estimates of mortality associated with long-term exposure to outdoor fine particulate matter. Proc Natl Acad Sci (USA). 2018;115(38):9592-7.

23. Lelieveld J, Klingmuller K, Pozzer A, Poschl U, Fnais M, Daiber A, Munzel T. Cardiovascular disease burden from ambient air pollution in Europe reassessed using novel hazard ratio functions. Eur Heart J. 2019;40(20):1590-6.

24. Clark LP, Millet DB, Marshall JD. National patterns in environmental injustice and inequality: outdoor $\mathrm{NO}_{2}$ air pollution in the United States. PLoS One. 2014;15(9):e94431.

25. Clark LP, Millet DB, Marshall JD. Changes in transportation-related air pollution exposure by race-ethnicity and socioeconomic status: outdoor nitrogen dioxide in the United States in 2000 and 2010. Environ Health Perspect. 2017 ; 125(9):097012, Epub ahead of print. https://doi.org/10.1289/EHP959.

26. Janssen NAH, Gerlofs-Nijland ME, Lanki T, Salonen RO, Cassee F, Hoek G, Fischer P, Brunekreef B, Krzyanowski M. Health effects of black carbon. Copenhagen: World Health Organization; 2012.

27. Atkinson RW, Butland BK, Anderson HR, Maynard RL. Long-term concentrations of nitrogen dioxide and mortality. Epidemiology. 2018;29(4):460-72.

28. Luben TJ, Nichols JL, Dutton SJ, Kiranne EF, Owens EO, Datko-Williams L, Meagan M, Sacks JD. A systematic review of cardiovascular emergency department visits, hospital admissions, amd mortality associated with ambient black carbon. Environ Int. 2017;107(Oct):154-62.

29. Tan Y, Dallman TR, Robinson AL, Presto AA. Application of plume analysis to build land use regression models from mobile sampling to improve model transferability. Atmospheric Chemistry. 2016;134:51-60.

30. Li HZ, Dallmann TR, Gu P, Presto AA. Application of mobile sampling to investigate spatial variation in fine particle composition. Atmos Environ. 2016;142:71-82.

31. Tan Y, Lipsky EM, Sateh R, Robinson AL, Presto AA. Characterizing the spatial variation of air pollutants and the contributions of high-emitting vehicles in Pittsburgh, PA. Environ Sci Technol. 2014;48(24):14186-94.

32. Eeftens M, Beelen R, de Hoogh K, Bellander T, Cesaroni G, Cirach M, Declercq C,

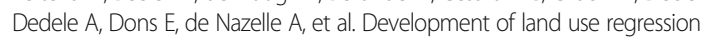
models for $\mathrm{PM}_{25}, \mathrm{PM}_{25}$ absorbance, $\mathrm{PM}_{10}$ and $\mathrm{PM}_{\text {coarse }}$ in 20 European study areas; results of the ESCAPE project. Environ Sci Technol. 2012;46(20):11195-205

33. Office of Environmental Justice, PA Department of Environmental Protection: PA Environmental Justice Areas Harrisburg, PA, 2019. https:// www.dep.pa.gov/PublicParticipation/OfficeofEnvironmentalJustice/Pages/PAEnvironmental-Justice-Areas.aspx. Accessed 24 Oct 2019.

34. Altman DG. Practical statistics for medical research. London: CCRC Press; 1991.

35. Faustini A, Rapp R, Forastiere F. Nitrogen dioxide and mortality: review and meta-analysis of long-term studies. Eur Respir J. 2014;44(3):744-53.

36. Thurston GD, Burnett RT, Turner MC, Shi L, Krewski D, Lall R, Ito K, Jerrett M, Gapstur SM, Pope CA Jr. Ischemic heart disease mortality and long-termexposure to source-related components of U.S. fine particle air pollution. Environ Health Perspect. 2016;124(6):785-94

37. Rosofsky A, Levy JI, Zanobetti A, Janulewicz P, Fabian MP. Temporal changes in air pollution exposure inequality in Massachsetts. Environ Res. 2018;161:76-86.

38. Karas D. Highway to inequity: the disparate impact of the interstate highway system on poor and minority communities in American cities. New Visions Public Affairs. 2015;7:9-21.

39. Mohl RA. Stop the road: freeway revolts in American cities. J Urban Hist. 2004;30(5):674-706.

40. Gilbert NL, Woodhouse S, Stieb DM, Brook JR. Ambient nitrogen dioxide and distance from a major roadway. Sci Total Environ. 2003;312(1-3):43-6.
41. Karner AA, Eisinger DS, Niemeier DA. Near-roadway air quaility: synthesizing the findings from real-world data. Environ Sci Technol. 2010;44(14):5334-44.

42. Rowangould GM. A census of the US near-roadway population: public health and environmental justice considerations. Transp Res Part D Transp Environ. 2013;25:59-67.

43. Mikati I, Benson AF, Luben TJ, Sacks JD, Richmond-Bryant J. Disparities in distribution of particulate matter emission sources by race and poverty status. Am J Public Health. 2018;108(4):480-5.

44. Mills IC, Atkinson RW, Anderson HR, Maynard RL, Strachan DP. Distinguishing the associations between daily mortality and hospital admissions and nitrogen dioxide from those of particulate matter: a systematic review and meta-analysis. BMJ Open. 2016;6:e010751.

45. Burnett RT, Pope CA 3rd., Ezzati M, Olives C, Lim SS, Mehata S, Shin HH, Singh $G$, Hubbell B, Brauer $M$, et al. An intergrated risk function for estimating the global burden disease attributable to ambient fine particlate matter exposure. Environ Health Perspect. 2014;122(4):397-403.

46. Di Q, Wang Y, Zanobetti A, Wang Y, Koutrakis P, Choirat C, Dominici F, Schwartz J. Air pollution and mortality in the Medicare population. N Engl J Med. 2017;376(26):2513-22.

47. Shin HH, Cohen AJ, Pope CA 3rd., Ezzati M, Lim SS, Hubbell BJ, Burnett RT Meta-anlysis methods to estimate the shape and uncertainty i nthe assoication between long-term exposure to ambient fine particulate matter and cause-specific mortality over the global concentration range. Risk Anal. 2016:36(9):1813-25

48. Xie W, Li G, Zhao D, Xie X, Wei Z, Wang W, Wang M, Li G, Liu W, Sun J, et al. Relationship between fine particulate air pollution and ischaemic heart disease morbidity and mortality. Heart. 2015;101(4):257-63.

49. Bai L, Shin S, Burnett RT, Kwong JC, Hystad P, van Donkelaar A, Goldberg MS, Lavigne E, Copes R, Martin RV, et al. Exposure to ambient air pollution and the incidence of congestive heart failure and acute myocardial infarction: A population-based study of 5.1 million Canadian adults living in Ontario. Environ Int. 2019;132:105004.

50. Presto AA, Dallman TR, Gu P, Rao U. BTEX exposures in an area impacted by industrial and mobile sources: source attribution and impact of averging time. J Air Waste Manag Assoc. 2016;66(4):387-401.

51. Yang Y, Ruan Z, Wang X, Yang Y, Mason TG, Lin H, Tian L. Short-term and long term exposures to fine particulate matter constituents and health: a systematic review and meta-analysis. Environ Pollution. 2019;247(Apr):874-82.

52. National Research Council. Using the American Community Survey: Benefits and Challenges. Washington, D.C: The National Academies Press; 2007.

53. ESRI. The American community survey - an Esri white paper. Redlands: Esri; 2014.

54. Folch DC, Arribas-Bel D, Koschinsky J, Spielman SE. Spatial variations in the quality of American community survey estimates. Demography. 2016;53(5): $1535-54$

\section{Publisher's Note}

Springer Nature remains neutral with regard to jurisdictional claims in published maps and institutional affiliations.

Ready to submit your research? Choose BMC and benefit from

- fast, convenient online submission

- thorough peer review by experienced researchers in your field

- rapid publication on acceptance

- support for research data, including large and complex data types

- gold Open Access which fosters wider collaboration and increased citations

- maximum visibility for your research: over $100 \mathrm{M}$ website views per year

At $\mathrm{BMC}$, research is always in progress.

Learn more biomedcentral.com/submissions 